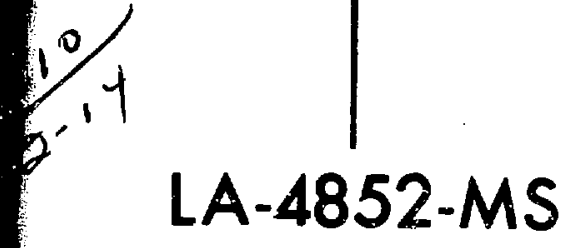

AN INFORMAL REPORT

\title{
Resonant Absorption of Laser Light by Plasma Targets
}


This report was prepared as an account of work sponsored by the United States Government. Neither the United States nor the United States Atomic Energy Commission, nor any of their employees, nor any of their contractors, subcontractors, or their employees, makes any warranty, express or implied, or ascumes any legal liability or responsibility for the accuracy, completeness or usefulness of any information, apperatus, product or process disclosed, or represents that its use would not infringe privately owned rights.

This report, like other special-purpose documenks in the LA. . . MS series, has not been reviewer or verified for accuracy in the interest of.prompt distribution.

Printed in the United States of America. Availabie from National Tachnical Information Service

U. S. Depart:nent of Commerce 52B5 Port Royal Road

Springtield, Virginia 22151

Prics: Printed Copy \$\$.00; Mierofiche $\$ 0.95$ 
LA-4852-KMS

An Informal Report

U.C-20

ISSUED: December 1971

\title{
Resonant Absorption of Laser Light by Plasma Targets
}

by

\author{
J. P. Freidberg \\ R. M. Mitchall \\ R. L. Morse \\ L. I. Reduinaki
}

This ruport we cropired st in secount of work enoninged by. the Unftud Setes Govomment. Nether

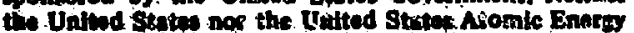
Commimion, her any of thet etoployes, nor any of

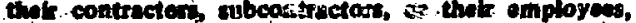

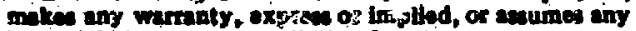

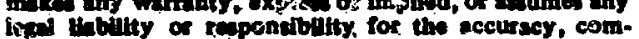

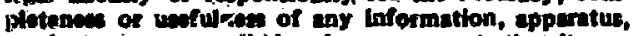

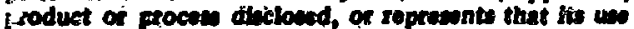
Fould sot infinge peivately owaed rishts. 


\section{REA. TANA ABSORPTION OF LASER LIGHT BY PIASYA TARGBTS}

by

J. P. Fre1dberg, R. W. Mitche11, R, Lo Morse and L. I. Rudo1nsk1

\section{ABSTRACT}

It 18 proposed that a resonant mechanism should cause significant absorption of energy from intense laser pulses in plasma targets, and that the enexgy should be deposited in such a way as to form a very non-Maxwellian high temperature tail on the electron velocity distribution.

Current interest in the controlled relecse of nuclear energy from laser-heated pellets of thermonuclear fuel has drawn interest to mechanioms by which laser light might be absorbed in the gurface nf zinil peilets. The large pulsed 1ight intengities which are required for this heating and are beginning to be avallable in absorption experiments put the Interaction of the laser sadiation with the InItaily solid target in the approximately collisionless regime. Binary collisinus between electrons drfiven by the wave flelds and lons (sometimes calligd Inverse brematrahlung) can cause some absorption and may be quite important in allowing a weak precursor of a pulse to lontze the target and give the aurface some thickness as aseumed below, but as the intenBlty Increases the fraction of the 11ght energy absorbed by collisions becomes amaller.

In thin letter we propose a resonant, col11sion" less absorption mechantem by which an inhomogeneous target plasme can absorb a significent frection of obliquely incident laser 11ght. We then show from numerical simulations that the energy is deposited In a very non-ifaxwelifan tall of the electron ve10city distribution. Preitminary work on a relativistic abooxption mechaniom is also nentioned. If the electron density of the plasma, $a_{6}$, and therefore the dialectric constent, 6 , are functions on $2 y$ of $x$, the 11 ght is incident with the wave vector $\bar{k}$ in the $x, y$ plane at an angle $\theta$ to the $x$ axis, and the $\bar{E}$ field is polarized in this plane, then the c.w. wave equation for the only nonzero component of the magnetic field, $B_{z}$, is

$$
\begin{aligned}
& \frac{d^{3} B_{z}(x)}{d x^{2}}-\frac{1}{c(x)} \frac{d g}{d x} \frac{d B_{z}(x)}{d x} \\
& +k_{0}^{a}\left(c-\sin ^{a} \theta\right) B_{2}(x)=0
\end{aligned}
$$

whexe $k_{0}=\omega / c$ is the free epace wave number, $B_{z}(x, y, t)=B_{z}(x) \exp \left[-1 \omega t+1 k_{y} y\right]$ and $k_{y}=k_{0}$ sin $\theta$. Consider the fantilnr dielectric constant for a cold plasme with a collision frequency $v$;

$$
c(x)=1-\frac{\omega_{p e}^{a}(x)}{\omega^{2}}\left(1+\frac{1 \nu}{\omega}\right),
$$

where $w_{p e}=\left(4 \pi m_{e} e^{2} / m_{e}\right)^{2}$ is the electron plasma frequency. In the collisionless 11 mitt, $w / w \rightarrow 0$, a resonent singulasty appears in the second term in Bq. (1) at the point on the ownsity profile where $\omega_{p e}(x)=\omega$ and, therefore, $e(x) \rightarrow 0$, (By contrast no such resonant eingulartty appears in the corresponding equation for light polarired normal to the plane of incidencs.) In this limit a fintte abeorption occure at the elngularity. When $\mathrm{Eq}$. (1) 10 integraked with a linar donesty gradient such that 
the dergaty rises linearly from wp 0 at $x=0$ to $\omega_{\mathrm{pe}} \rightarrow \omega$ at $\pi \neq \mathrm{L}$, and the connection formules at the alngularity are given only by $v>0$ and $v / \omega \rightarrow 0$, the power absorption coeffictents plotted in $F 18$. 1 xe obtaineti. The maxims indicate thet there so an opindmum angle of Incidence for abaorptson. For ko 9.0 this 18 oeen to be at $\left(k_{0}\right)^{\frac{3}{3}} \sin ^{2} \theta=0.7$ or $\theta=$ 230. Boz large L, 1.e., weaker density gradients, the optim angle is amnller, 1.e., more nearly norrul incidence. Flgures $2 \mathrm{a}, 2 \mathrm{~b}$, and $2 \mathrm{c}$ shot real and imeginary parto of tho nonzero componante of the oolut son of $\mathrm{Eq}$. (1) then $\mathrm{k}_{\mathrm{o}} \mathrm{L}=10$ and $\theta-23^{\circ}$. The

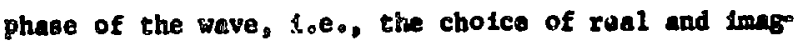
Inary parte is taken to be such that $B_{z}$ lo pure real at $x=2($ F $=2 \mathrm{~g})$. The absorption 10 coused by the nonzero $B_{X}$ wave fleld, which only occurs when there Is non-normal incidence with this polarization, and which drives plasma oscillations in the $x$ direction with frequency $w$. At the critical ourface where w * w $\omega_{\text {pes }}$ the natural frequency of these plasma oscillations, their amplitude becoma vary large, In fact Inversely proportional to $v$, and as $v \rightarrow 0$ the collfsional energy diselpetion moothly approuches the fintse 11mit plotted in Fig. I. Jrow Fig. 26 and $2 \mathrm{c}$ tho is componant of the Poynting vector is a abop funceion, finte and constant to the left of:

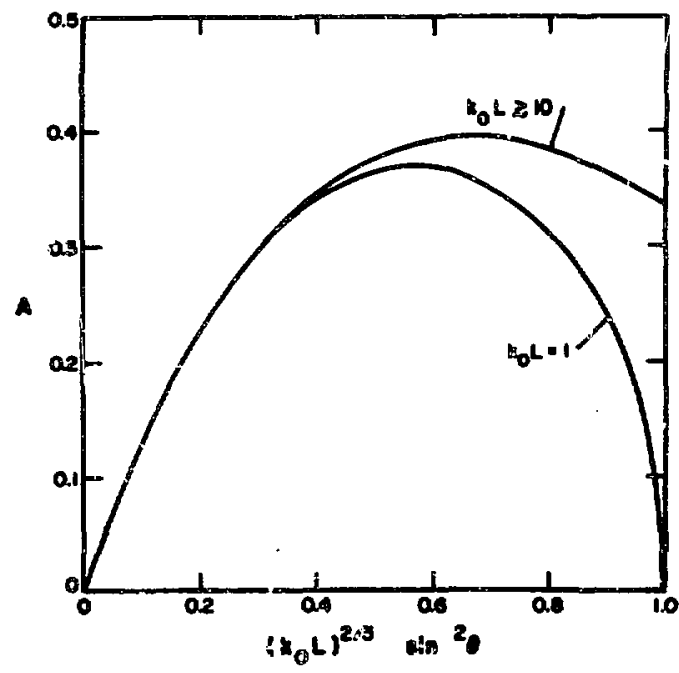

F18. 1. Rate of ewrsy absorpt1on, $A_{2}$ as a funetion of angie of inctians, $\theta$, vecum veve nuber, ko, and detance from the frout edge to the eritical ourface, I.

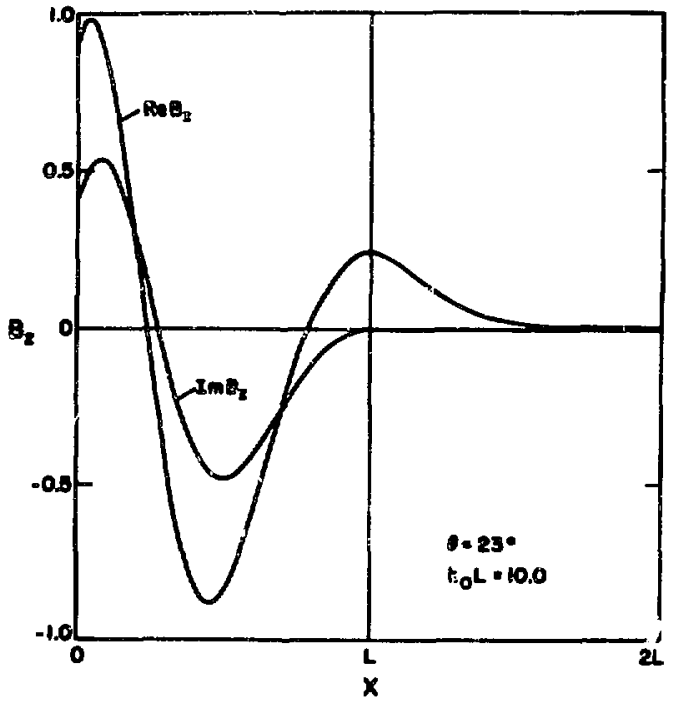

848. 2a. $B_{\mathrm{g}}$ ve $x$ for the cere $k_{0} L+10$ at the optimis angle of $\theta-230$ In the limtt $v / \omega \rightarrow 0$.

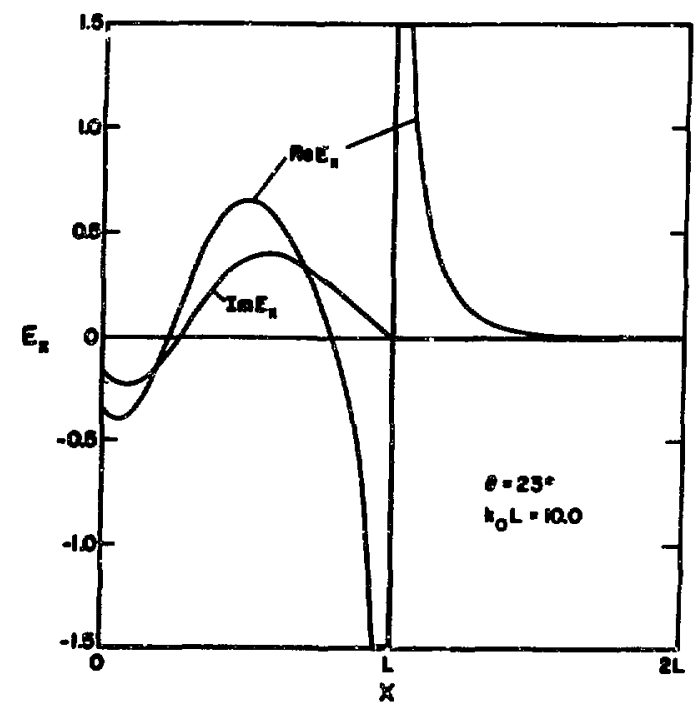

Fig. 2b. I, va $x$ for the cued kol 10 at the optinu anglo of $\theta$ a 230 in the linit $v / 0-0$. 


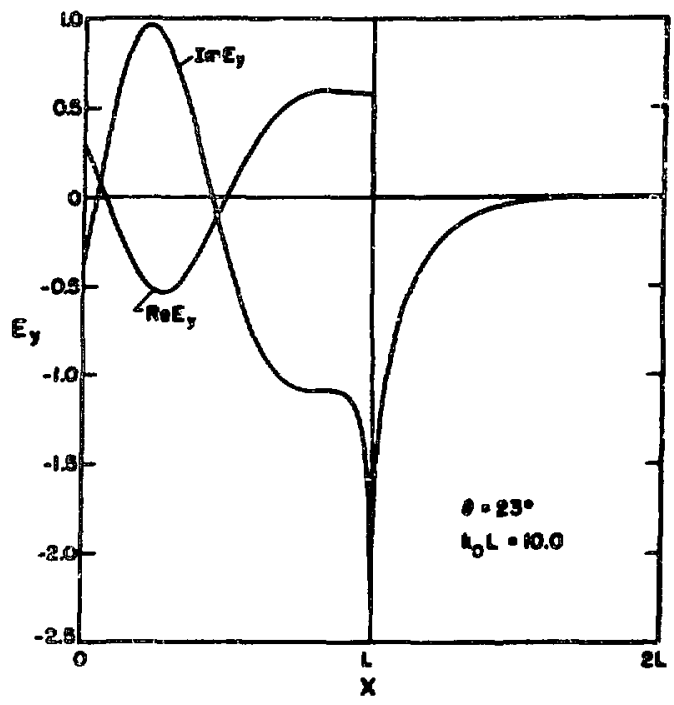

Fig. 2c. $B_{y}$ vg $x$ for the case $k_{0} I=10$ at the optiwum ansle of $\theta=230$ iv the 1init $v / \omega \rightarrow 0$.

$x=I$ and zero to the right with ReB $\left(F 1_{B}, 2 c\right)$ where $\mathrm{ReB}_{z}$ ( $\mathrm{Fig}, 2 \mathrm{a}$ ) remains fintte. This is conolstent with a very large real $x$ componant of the electron current, $J_{x}$, at $x=I$ which to in phase with, and therefore absorbs energy from the electromagnetic part of $\mathrm{ReB}_{x}, \quad\left(\operatorname{ImB}_{x} 18\right.$ zero at $x$ : $I_{0}$ F1g. 2b, except for delta funct 10 a there which does not appear explicitly in the calculationo and does not contribuite directly to the absorption in this approxtantion.) This part of $\mathrm{B}_{x}$, which drtvee the oscillatione in the firet place and witch to noaninguiar at $x=I$, is reduced to zero by tho changlag $\times$ projection as $\bar{k}_{0}$ tusne towerd normal incydence and to reduced by the increased tuaneling distance frow the elaselcal turning polnt where $\omega_{p e}{ }^{a} / \omega^{2}-\cos ^{2} \theta$ to $x=I$ where $\omega_{n e}{ }^{2} / \omega^{\circ}-1$ when $\theta$ becomen 1arge. Hence there is a meximum absorption at Intermodiate values of $\theta$, en axguent which car be forralised to oatimate that the neximum occure whare $\left(h_{0} L\right)^{\frac{8}{3}} \cdot 10^{2} \theta=(i)^{3}$.

The linoar donolty profilo is qualitatively like wont of the profila expected in prectice who an da1tielly whaxp ourface axpands a bit tato the vacuin during heating, nosatime becaus of a solk precuraor before a voct maln pulea. Of coure the magnitude of the abaorption w11 depend nomswhat ou the detalls of the profile. For Inatance a more wearly flat opot in the profile non the critical aufface can enhance tha absorption.

Colligfonal resonant abeorption of obliquely Incident radiation hes been otudied previouly by tha model uod above, but without numerical Integrations, In the context of microwave propagation in the lonosphere, (1) (also ozher refexences contadned In Ref. 1). Besentelly the effect seane to be otserved In seudies of the Infrared irracilation of thin metal filme. (2)

The preceding linearized treatment tiplicitiy arsume that the amplitude of the $x$ dieplaceanats of the electrons which in steady otate is

$$
f(x)=\frac{m\left[w^{3}-w_{p e}^{2}(x)-1 w_{0}\right]}{a w^{2}}
$$

where $B_{d}$ is the electromagnetic part of $B_{x}$ refierred to bove which drives the oscillations, is so amail that it can be neglected.

However, for any given aplitude of wave fleld there 10 wom region around the critical surface where thie do not true when $v / \omega \rightarrow 0$ and where, in fact, the approximate condition for phase pose breaking, $|\mathrm{d} g / \mathrm{d} x|>1$ s satiofied. In this col11clonlese regime the broaking of the electron plasm waves or oscillations in the resount rogion taked the place of collialone in 1imiting the pitude of the oac112atione and thereby aboorbing wave enar $8 y$. since in mot applications thte procese only lintes the electron osclllations near the criticel ourfacn, at doas the olgnificant collialonal demping when $0<v / 0<8$, thoy appoar oseent1ally the samo in the Largo and the abeocption raten of $\mathrm{FIg}, 1$ can be applled to collietonlese canes as 11.

If order to raach this understanding of the collielonlese resonsnt ebsorption, which it quite conlinear, it was neceenary to treat the problem by partscle-1n-cell numerical of inlation. (3) Eince the problen is basically two-dimastonal (except for a veralon of the problen which if infinita but not perlodis io $y$ ), a celf-conalefsine trestrant required fully stectrongate tivondinelonal (10 $x$ and $y$ ) -fendations wich were dum uping the wethod of 4ppardte 8 in Daf. 3 with parlodictey in $y$. The reoulte of thace cwo-dteonotonal olnulatione, wheh 
will be published in a more complete article, show that the following one-dimensional simulation method gives a qualitatively correct picture of the coll1sionless resonant electron heating in addition to affording higher spatial resolution. An oscillating $E_{d x}(x, t)$ field is arbitrarlly imposed, as in Eq. (3) above, with a smooth bel1-shaped profile in $x$ centered at $x=I$, and broad enough to extend well on either side $u r$ the region where the resonant $a b$ sorption occurs. The elections, and the lons if they are mobile, move in $x$ and their resulting charge density is used to compute $E, 1$ additional electrostatic $E_{x}$ field from Folsson's equation as if the system were Independent of $y$. This $E_{x}$ determines the motion of the particles. In the dimensionless units of the simulation, Fig. 3, a particle with unit velocity travels a unit distance in unit $t$ ime, and the frequency of $F_{d x}$, which is of course enual to the plasma frequency at the critical surface, $18 w=1, i^{\circ} e .$, a period of the driving field is $2 \pi$. The maximum amplitude of $E_{d x}$ at $x=L$ Is such that a free electron would oscillate with a maximum $x$ velocity, $v_{y}$, of one, which is much less that the resonantly eninanced values seen in Fig. 3 . At $t=0, F i g .3 a$, the electrons, which are cold, and the lons, which are flxed, heve a linear density profile which rises from zero at $x=0$ to twice the critical density at $\mathrm{x}=2 \mathrm{~L}=600$ with the critical density at $x=L=300$. The sinusoidal oscilletions of $\mathrm{E}_{\mathrm{dx}}$ begin at this time and the osc1llations bulid up without breaking until at $t=$ 41 through 43, Figs. $3 b$ and $3 c$, breaking occurs for the first time. A simple analysis like that of Eq. (3), with transients included instead of $\nu \neq 0$ if one wishes, shows that oscillations on either side of $x=L$ should be $180^{\circ}$ out of phase with one
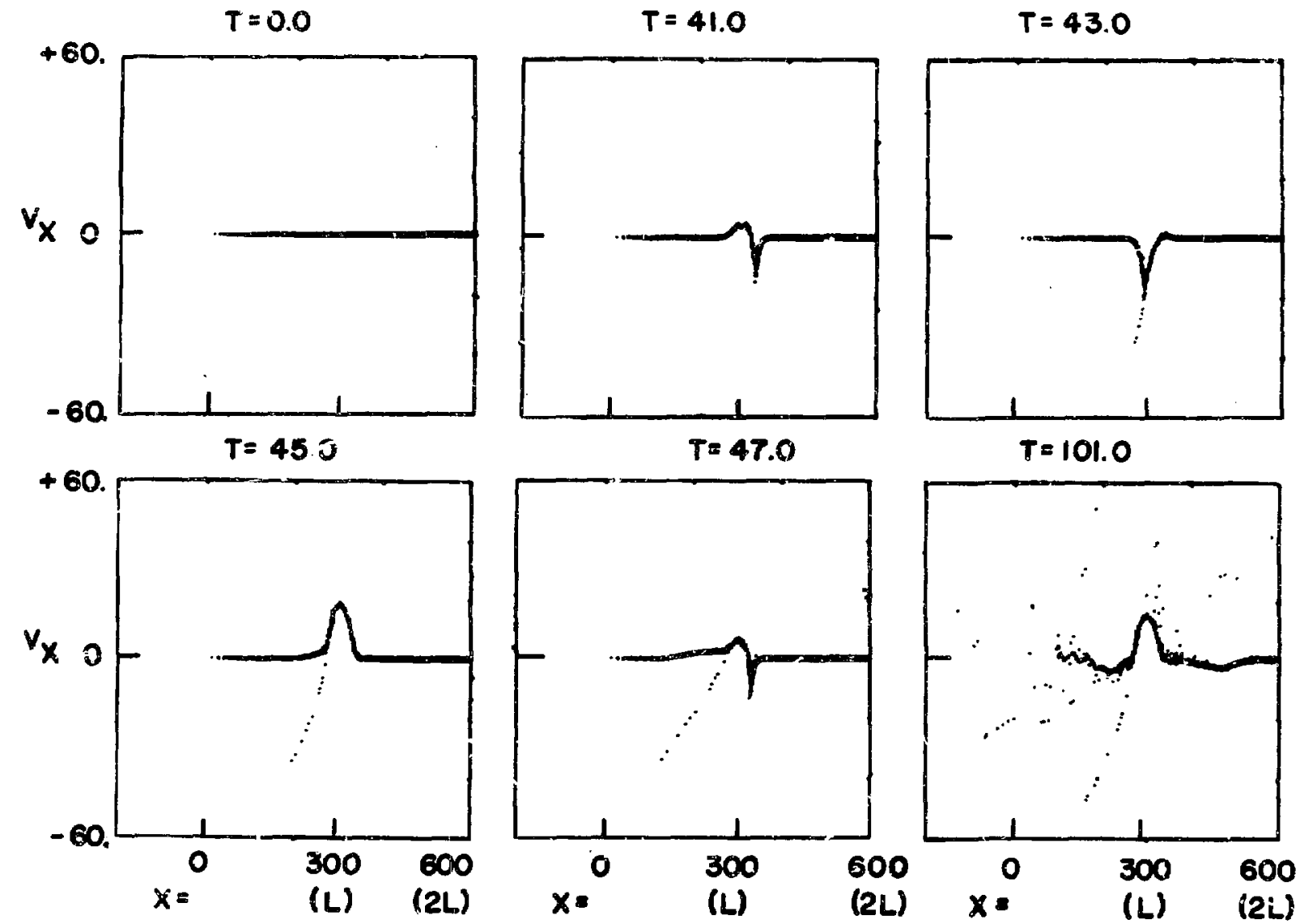

F1g. 3. Electron phase space plot of a one-dimensional simulation of the collisionless absorption. Note the fey scattered electrons at large energies in $a, e$, and $f$. 
another with those very close to $x=$ L boing $90^{\circ}$ out of phase with both in such a sense that the total wave motion near $x=L$ appears like a sequence of waves grcwing up on the high cansity side and moring toward the lower denstty site follows by a rarefaction-like motion back to the high density side ag seen In Fig. 3d at $t=45$. Hence, ac observed here, the breaking should occur to the left, 1.e., toward the vacuun, and not to the right. In $F 1 g .3 e, t=47$, the high energy electrons from the first breaking are moving toward the vaculas where they will be reflected back to tha right by = charge separation potent $1 a 1_{g} \mathrm{Fig}$. 3f. The breaking process at the critical surface is about to repeat as it does on every cycle from then on in about the same way 1f, as in this code, the hot electrons are absorbed at the right wall and replaced by reemission of cold electrons. The energy ls then effecrively deposited in the Interfor of the target by collisionless electron thermal crnductivity. Figure $3 f$ shows the situstion much later at $t=101$. Plainly the heated electrons are mich more energetic than they would be with the maximum freo electron velocity of $v_{x}=1$ and thus consticute $a$ very non-blaxwellan high temperature tall on ac otherwlse essential cold electron velocity distriburion. Figure 4 showe the distribution of lons at $t=200$ from an otherwise Identical run but with mobile $\mathrm{H}^{+}$tons. Electron presoure is causiug the front surface lons to blow off with a rather high energy and is pushing lons away from the critical gurface, which has the effect of cemporarily partialiy quenching the resonance.

Recent one- and two-dimensional simulattons including relativistic particle dynamics have aiso shown that when the iaser wave fleld is sufficiently intense a significant fraction of the incident energy is Imparted to the electrons in a manner similar to that seen above by the oscillating radiation pressure, 1.e., the $\bar{V} \times \overline{\bar{B}}$ force. Here, however, polariration and angle of inctdence are not so important and the resulting electron energy alstribution shows less of the two-temperature structure seen above.

\section{ACKNOWIBDGEYIBNTS}

This work was first presented at the September 23-27, 1971 Gordon Conference on the Interaction of Laser Light with Matter.

\section{REPBRBNCRS}

1. P. Hirech and J, Shouys, Radio Sclence JournaI of Research NBS/UisNC-URSI, Vo1. 69D, No. 4, 521 (1965).

2. M. Skibowsk1, B. Fenerbacher, W. Stelmann, and R. P. Godwin, Z. fïr Physik 211, 329 (1968).

3. R. L. Morse acd C. W. NLalson, Phys. Fluids 14 , 830 (1971).

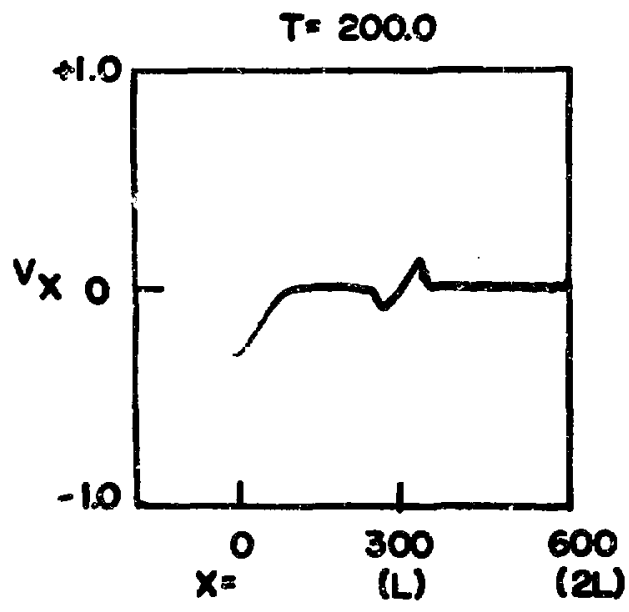

E1g. 4: Phase space plot of at 10tw. 